\title{
Development of a Computer-Assisted Personal Interviewing (CAPI) Methodology to Assist the Photovoltaic Design Process
}

\author{
Samuel Roberto Moraes ${ }^{1,2}$, João Murta-Pina ${ }^{2,3,{ }^{*}}$, Miguel Santos ${ }^{1}$, Tiago C. Pereira $^{2}$, \\ Fernando Monteiro ${ }^{2,3}$, Ricardo Matos ${ }^{4}$, Filipe Matos $^{4}$, Diogo Pinto ${ }^{4}$, Francisco Oliveira ${ }^{4}$, \\ Sofia Correia ${ }^{2}$, and André Mora ${ }^{2,3}$ \\ ${ }^{1}$ Engibase - Engenharia e Construção, Lda., 2830-271 Barreiro, Portugal \\ ${ }^{2}$ NOVA School of Science and Technology (FCT NOVA), 2829-516 Caparica, Portugal \\ ${ }^{3}$ Centre of Technology and Systems (CTS UNINOVA), 2829-516 Caparica, Portugal \\ ${ }^{4}$ Digitalmente, Novas Tecnologias de Comunicação, Lda., 3860-384 Estarreja, Portugal
}

\begin{abstract}
Computer-Assisted Personal Interviewing (CAPI) is a wellknown methodology in the development of social surveys. In this work, CAPI is used to guide the flow of a questionnaire aiming for the acquisition of data and information fundamental to optimise a photovoltaic (PV) design. The questionnaire is implemented in an app, developed in the frame of the PV SPREAD project, which is aimed to support the supplier/designer of PV plants during all the stages of its development. To demonstrate how different choices of a client, specified during the interview with the designer, will have distinct economic results, two configurations are presented. In the first, the system is allowed to determine and use the optimum inclination angle of the modules, while in the second a low angle is selected by the client, to comply with aesthetic restrictions. The first configuration improves naturally the internal rate of return of the investment, as this is the optimising cost function, but the system allows comparing both ones. The CAPI methodology and its use in the context of PV design show to be a relevant tool to support designers and to provide more informed investments to clients.
\end{abstract}

\section{Introduction}

Computer-Assisted Personal Interviewing (CAPI) is a type of interview which is conducted with the support of a computer [1]. CAPI has been extensively used and analyzed in the context of Social Sciences but could be extended to several other fields, particularly to the context of assisting the photovoltaic (PV) design process, as proposed in this paper. This process has a primordial stage related to enquiring the client, before commissioning the system, to obtain information of a very distinct nature (financial, electrical, aesthetical, among others). In this interview, the respondent may also pose several questions, e.g. related to technical aspects of PV technology, existing subsidies, or associated business

\footnotetext{
*Corresponding author: jmmp@fct.unl.pt
} 
models. These should be answered in a language adequate for non-experts, preferably supported by diagrams, photographs, and technical data, aiming to engage the client, to secure him in his legitimate expectations, and to establish an environment of confidence [2]. This is fundamental for accelerating photovoltaic systems deployment and dissemination, which will contribute to assisting the Energy Transition [3]. Besides, dispersed PV, up to a few hundreds of $\mathrm{kWp}$, play a major role in this process, and are often installed by micro and small enterprises, where single technicians are in charge of conducting the whole process, from the commercial approach to the design and final deployment.

The CAPI paradigm has many advantages when comparing to regular Paper-Assisted Personal Interviewing (PAPI), e.g., data quality improvement since the computer manages and shows the questions, while validating answers, in an appropriate flow, and the interviewer focuses only on the interview itself [4-6]; economy of resources if the acquired technology is also massively used in others surveys, and particularly if these are large-scale and continuous $[5,7]$, and time-saving in data processing as the data may be sent to a server immediately [8].

A CAPI questionnaire is used to acquire data $[9,10]$ with a clear objective. In short, to develop a questionnaire the first step consists of identifying all the variables and define how to obtain them [11], afterwards create the questions and pretest them mostly to assess the meaning of the words, the flow and naturalness of the interview, and the interest and attention of the interviewees [12], among other aspects.

There are two basic types of questions, namely open and closed ones. Open questions are the ones that have no predetermined possible answers and are used mostly for the respondents to expand their responses freely [13]. These allow for rich answers, but they may require interpretation and their analysis may turn complex and time-consuming [4]. Closed questions are the ones that have a predetermined set of alternatives that the respondent should choose. They should be used only when the researcher identifies the variables of interest very well and wants to get quantitative information about them [14].

The formulation of questions is of the utmost importance to obtain precise and useful information. For instance, double-barreled questions, where more than one subject is asked in a single question, but only one answer is allowed (e.g., "yes" or "no"), should be avoided [11]. Questions should also be formulated to avoid occurrences as telescoping (tendency to perceive events temporally displaced, e.g., closer to the interview than they are), social desirability, and variation in the response function [4]. The use of strong words can annoy some respondents [15] and it is important to avoid acronyms, jargon, and technical terms [11].

CAPI questionnaires have been used for medical research [16-20], electoral surveys [21], education-related research [22], and household surveys [23], among others. No literature was found on the application of such a paradigm to assist the PV designer in the interview process to obtain the required characteristics for developing an optimized project.

When considering only the PV modules, the data needed to assess its performance in a given location, with defined azimuth and inclination, is straightforward, and often the irradiance in the plane of the array and the ambient temperature is enough [24]. For small scale studies, statistical/modelled time series are freely available, see e.g. the Photovoltaic Geographical Information System (PVGIS, https:/ec.europa.eu/jrc/en/pvgis) from the European Commission Joint Research Centre. Nevertheless, practical cases pose many degrees of freedom to the problem of optimizing a PV plant, and full optimization may be unfeasible. Among many of those design variables, the PV designer must look out for shadowing sources, study the most suitable protection system, and find where to install several pieces of equipment depending on their technical requirements [2]. From an economical point of view, the most important factors are the investment cost, amount of 
energy produced by the system, credit taxes, and government incentives [25]. In selfconsumption schemes, where e.g., the surplus energy injected in the grid may be remunerated, the produced energy is not the most relevant parameter to evaluate the economic criteria (as the internal rate of return or the payback period) that usually drive the optimization process. Rather the time series of the average instantaneous power (typically over 15 min periods) is used, as this must be compared to the consumption to determine the energy balance. The saved energy and surplus energy may have a rather different monetary value.

Besides the interview itself, mobile devices as tablets or smartphones are also a valuable tool to allow obtaining and processing several on-site data, as photographs (of the facilities, energy bills, electrical panels, shadows), roof inclination, or distances, among many other. There are several apps and platforms for assisting the PV designer in distinct aspects, some integrating, e.g., with Google Maps, namely assessing the available area, optimum orientation, and inclination of modules, local shading, energy production, or to analyze shadows or develop building-integrated photovoltaics projects, see, e.g., EasySolar (easysolar-app.com/), StepSolar (steprobotics.com/) or Onyx Solar (www.onyxsolar.com/ photovoltaic-estimation-tool), among many others.

None of the software previously mentioned focus on the main concern developed in this paper, that emphasis in helping the designer with the data collection (through a CAPI questionnaire with questions and instructions to the interviewer), and afterwards, to create the best possible project with the information acquired.

This paper is organized as follows: in the next section, the project where the CAPI methodology is being developed (PV SPREAD) is described. After that, in Section 3, a case study describing the application of this methodology is shown, highlighting the differences that may arise from distinct information and preferences provided by the client. These differences are analyzed and discussed in Section 4, namely from an economic perspective. Conclusions and future work are described in Section 5.

\section{The PV SPREAD Project}

PV SPREAD is the acronym of the project "Stimulating PV REliance, Advance and Dissemination", funded in the frame of the Portugal 2020 Program, that aims, among others, to promote the joint R\&D between academic and industrial partners. PV SPREAD is being developed by a consortium of two companies and one academic partner.

\subsection{The PV SPREAD Ecosystem}

This work is being developed in the frame of the PV SPREAD project (https://pvspread.com/en), whose vision is to develop an ecosystem aiming at supporting unprecedentedly the supplier/designer of PV plants throughout all the design stages, automating several tasks and providing optimal designs.

The PV SPREAD ecosystem is built by a set of hardware and software tools, with associated methodologies, and is envisaged to address all the stages of the PV project cycle, starting from a pre-commercial stage, supporting the contact with clients and on-site information gathering, until the development of the optimum project.

The ecosystem is represented in Fig. 1 which illustrates the PV SPREAD concept, although this work only describes the CAPI methodology. The first step is to gather on-site all the characteristics of the client's facilities that are needed for developing the project through an app that also implements the CAPI methodology. A low-cost portable energy analyzer has also been developed, to measure and $\log$ load diagrams, as these are 
fundamental for self-consumption studies. The acquired data is sent to the Cloud, to be used in the optimization process. The designer also inputs optimization parameters through a Web platform, where a database with all the PV components and costs is available. Artificial intelligence-based multiobjective optimization algorithms run in the Cloud, to provide a report with the optimal project (optimal PV rating and configuration) and investment indicators, as the internal rate of return (IRR), net present value (NPV), and the investment payback time (IPT).

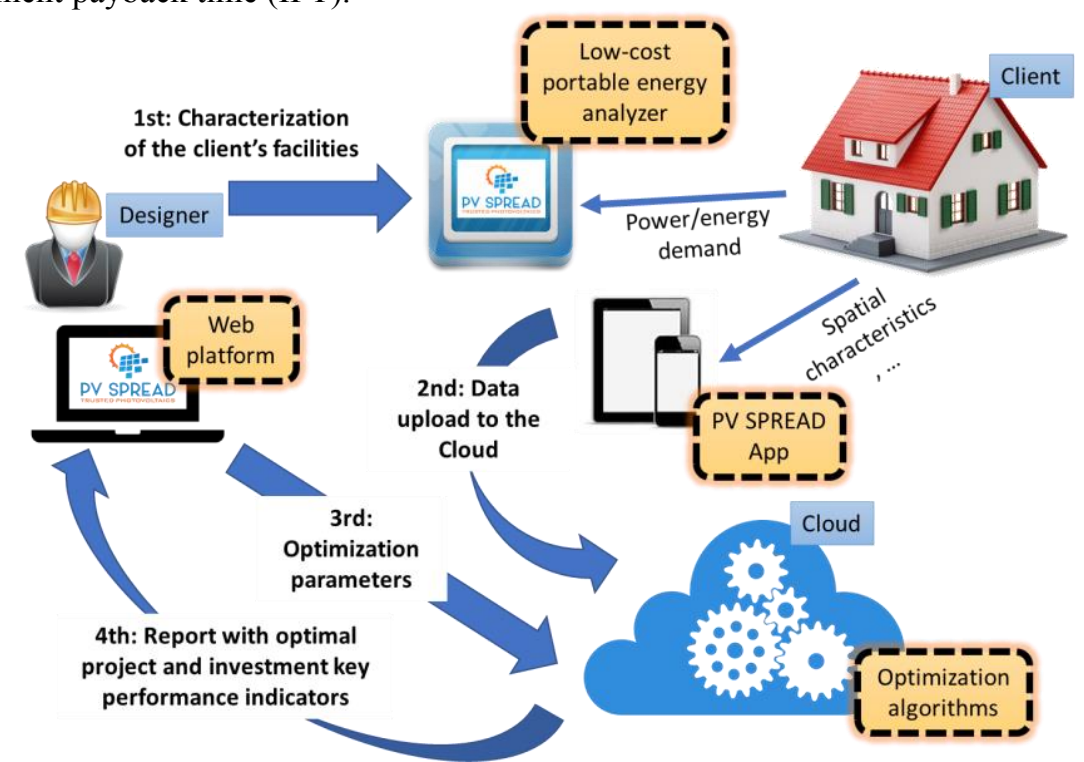

Fig. 1 Diagram of the PV SPREAD concept. Dashed boxes indicate specific PV SPREAD developments.

As mentioned, the app aims at supporting the designer, conducting the interview with the client, allowing collecting data, and perform the spatial characterization of the facilities. There is a great variety of information that the designer should get on-site, namely procedural (e.g., address, delivery point code), financial (e.g., loan requirements), or energy consumption related (e.g., energy bills, load diagrams), or aesthetical (e.g., modules colour or inclination, to avoid being visible from the outside). Other most relevant information where mobile devices can benefit the project is related to assessing shadows from nearby obstacles (like trees or buildings), for which PV SPREAD uses the mobile device integrated camera and image processing to determine the solar apparent path and its intersection with those obstacles. Other sensors are used to measure, e.g., roof inclination or distances to be covered by $\mathrm{DC}$ or AC cables, among others. These will be later integrated into the optimization algorithms.

The CAPI methodology is implemented in the app and the designer may change from the interview to the field measurements and vice versa, e.g. to collect images and measurements on a visit with the client while performing the interview.

\subsection{The CAPI Methodology}

A CAPI questionnaire flowchart was created to allow gathering all the information required for developing an optimal PV project. Besides the literature, the development of the questions had also the support of experienced technicians in several of the addressed areas. 
The CAPI global flowchart, shown in Fig. 2, represents the main stages of the interview with the client. In each stage, the app user may change from the interview to the field measurements and vice versa, as mentioned. The app also provides detailed information to support the interviewer (in the case he has no background or expertise on PV systems) as well as the respondent, of the technical reasons that motivate each question and their impacts on the performance of the PV system. In each stage, the information may be complemented with photographs where comments can be attached. The main aspects of each stage are:

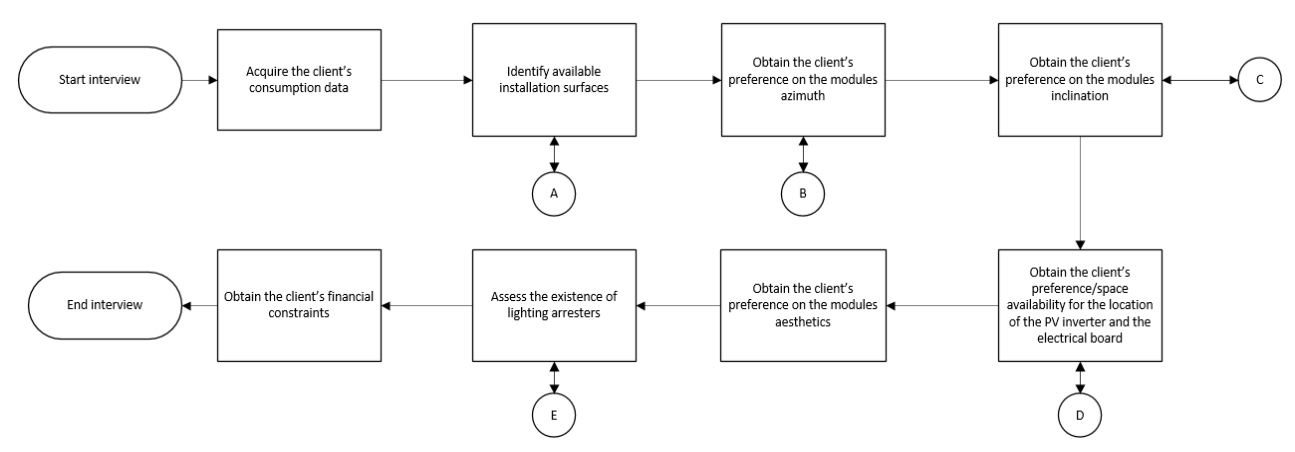

Fig. 2 Flowchart of the CAPI methodology.

- Identify the client, its reference number, and address, which will allow obtaining the temperature and irradiance data for the estimation of PV production.

- Acquire the client's consumption data, which is mandatory in self-consumption schemes since the economic valuation of the PV system will be derived from the instantaneous balance between consumption and production. From 2019, legislation in Portugal only considers these schemes for prosumers, which is the PV SPREAD target. Other aspects are questioned here, for instance, if the client is expecting to acquire a piece of equipment that could impact the demand, this may affect the optimal design. An important aspect addressed here is also if the premises already exist (and have a past demand) or if a future one is being considered (where demand should be typified).

- Identify available installation surfaces, in the client's facilities, which may receive the PV modules. This is set-up in a Google Maps interface integrated into the app, and the client chooses (or receives a suggestion) which surfaces are available, as well as which installation method.

- Obtain the client's preference on the modules' azimuth, e.g., if a building is not facing south, the client may decide if the modules should be facing south or be aligned to the building, or if the system should find the optimum azimuth (which is not necessarily south).

- Obtain the client's preference on the modules' inclination, e.g. on flat roofs, the client may prefer that the modules are not visible, for which a low inclination angle should be defined, or may leave the system to determine what is the best inclination.

- Obtain the client's preference/space availability for the location of the PV inverter and the electrical board. The client may have technical spaces where the PV inverter should be located, and the designer should assess, e.g., if there is 
available space at the electrical board to connect the AC cable from the PV plant, or if a new one is required, which also requires space.

- Assess the existence of lightning arresters and other protection systems. If a lightning protection system is available on the building, the PV system must be connected to it [2].

- Obtain the client's preference on the modules' aesthetics, e.g., there are currently several technologies, like thin-film, and colours available, from which the client may be allowed to choose. This is supported by images.

- Obtain the client's financial constraints, e.g., if a client needs to get a loan to acquire the PV system, this impacts the economic criteria, as interests will add to expenses. On the other hand, a maximum budget may be set by the client, with or without the need for a loan.

The CAPI may run simultaneously with field measurements (see Fig. 3), e.g., if the client is interviewed when visiting the future location of the PV modules. The same mobile device that runs the CAPI is used for those measurements, and the interviewer may switch among those tasks.

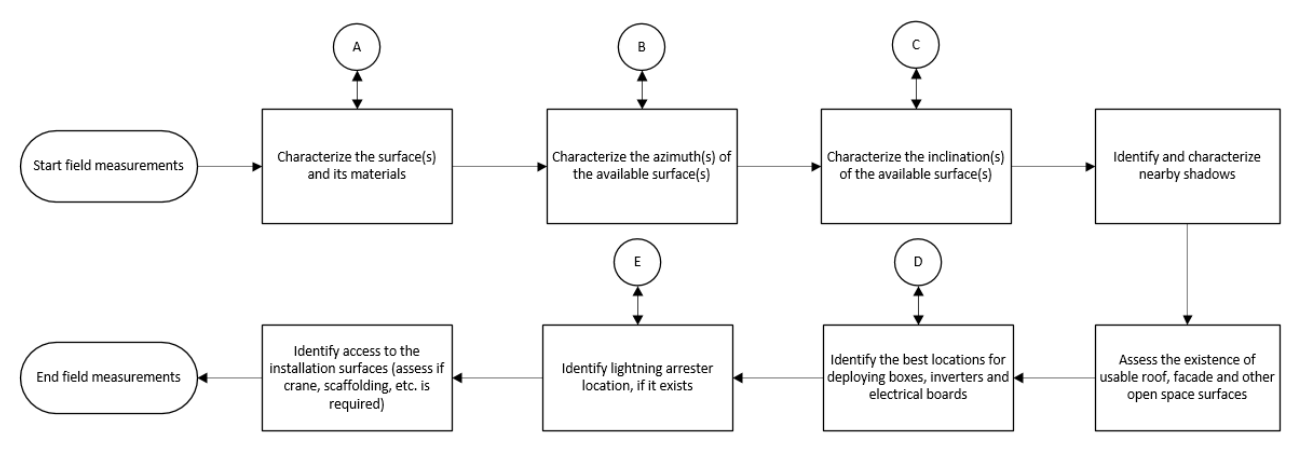

Fig. 3 Flowchart of the fieldwork methodology.

The following are brief comments related to the main aspects of fieldwork:

- Characterize the surface(s) and its materials, namely if it is ground, roof, and the type of material (e.g., type of soil, as sand, for ground, and/or type of roof, as, e.g., tile clay, galvanized sheet or fibre cement).

- Characterize the azimuth(s) of the available surface(s), which is assessable through the compass integrated with the mobile device.

- Characterize the inclination(s) of the available surface(s), which can be assessed through the inclinometer of the mobile device, if not horizontal.

- Identify and characterize nearby shadows. In the frame of the PV SPREAD project, a tool to evaluate the effect of shadows due to trees and buildings, or any other obstacle, is being developed. It uses the camera of the mobile device to assess the Sun's path in the sky and to detect those obstacles.

- Assess the existence of usable roof, facade, and other open space surfaces, which can be photographed and annotated.

- Identify the best locations for deploying boxes, inverters, and electrical boards, the same as in the previous item. Linear distances can also be measured with the mobile device. 
- Identify lightning arrester location if it exists. The same as in the previous item.

- Identify access to the installation surfaces (assess if crane, scaffolding, etc. is required). The same as in the previous item.

By using this application with CAPI methodology, the user will have gathered all the client-related data needed to design the optimal PV generator. These data will be complemented by the material, equipment, and prices (e.g., man-hour costs) of the designer, which are stored and may be updated through the PV SPREAD Web platform (see Fig. 1).

\section{Case Study}

\subsection{Description of the Consumption Facilities}

The CAPI methodology was tested to design a PV plant to be deployed on the roof of a hotel located in the central region of Portugal. Different choices of the client will have an impact on the design of the plant, and these will be assessed in this section. The hotel has a telemetering system, allowing a $15 \mathrm{~min}$ resolution of the consumption time series. There is no intention to acquire new equipment that could impact the consumption and several energy-efficiency related measures (e.g., replacement of existing lights by LEDs) have already been implemented. The roof is horizontal and made of concrete, for which support structures for the PV modules will be used.

The flowchart in charge of acquiring the client's consumption data can be viewed with details in Fig. 4.

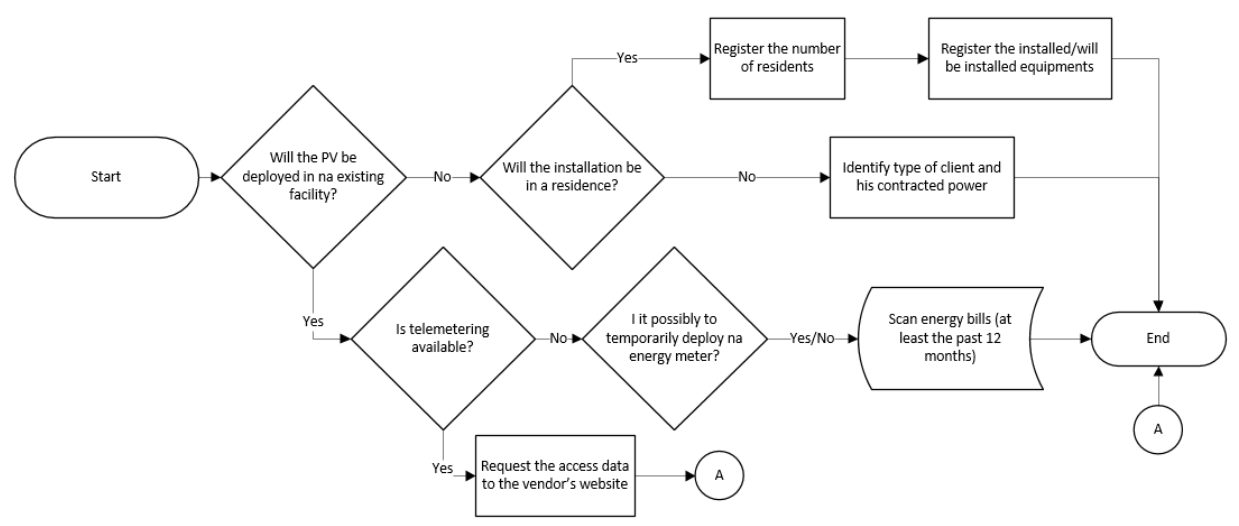

Fig. 4 Detail of the process "Acquire the client's consumption data". The mentioned energy meter may be the one developed under PV SPREAD.

Since the case study concerns a hotel, seasonality in the energy consumption is expected, among high- and low- seasons, as verified in Fig. 5. The demand profile is adequate for self-consumption, as it matches profile variation (higher in summer, lower in winter), and it shows a considerable minimum plateau throughout the days (e.g., around 20 $\mathrm{kW}$ in February, and more than $40 \mathrm{~kW}$ in August). 


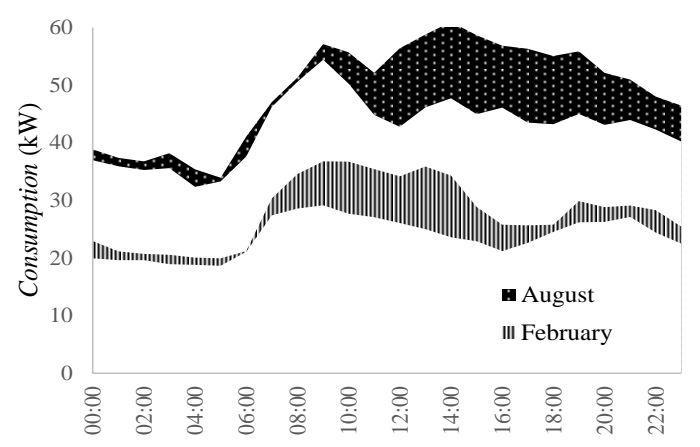

Fig. 5 Range of average electrical energy demand in the analyzed facilities, in high- (August) and low-season (February) months.

The hotel (which is not identified, due to data protection issues) has a rectangular horizontal roof, with an available clear area of $20 \times 25 \mathrm{~m}^{2}$, and an azimuth of $28^{\circ}$ (South is defined as $0^{\circ}$ and West as $90^{\circ}$ ). There are no shadows due to nearby buildings or trees.

The energy tariff of the hotel (including energy and access to grids), which is fundamental for self-consumption studies, as it dictates the monetary value of the saved energy, is described in Table 1, according to each time-of-day period. The client has a weekly cycle contract, meaning that weekdays, Saturdays, and Sundays have different timeof-day periods.

Table 1. Energy Tariff of the Client

\begin{tabular}{|c|c|}
\hline Time-of-day period & Value \\
\hline Peak & $0.1236 €$ \\
\hline Half-peak & $0.1075 €$ \\
\hline Off-peak & $0.0702 €$ \\
\hline Super off-peak & $0.0694 €$ \\
\hline
\end{tabular}

\subsection{Photovoltaic Parameters}

The main parameters of the PV modules used in this work are described in Table 2.

Table 2. Parameters of the selected PV module

\begin{tabular}{|c|c|}
\hline Parameter & Value \\
\hline Rated power & $310 \mathrm{Wp}$ \\
\hline Nominal Operating Cell Temperature (NOCT) & $44{ }^{\circ} \mathrm{C}$ \\
\hline Temperature coefficient of power & $-0.42 \% /{ }^{\circ} \mathrm{C}$ \\
\hline Module area & $1.652 \times 0.997 \mathrm{~m}^{2}$ \\
\hline
\end{tabular}

\subsection{App and the CAPI}

As already mentioned, the CAPI methodology, and the associated fieldwork, is implemented in an app, developed for the PV SPREAD project. In this paper, the effect of 
distinct choices of the client in the optimal configuration of the PV plant is analyzed. These choices will be related to their inclination.

Fig. 6 shows screenshots of the app developed for Android smartphones, with the main menu interface, as well as the moments in the interview where it starts the questionnaire with the client and the beginning of the fieldwork.

\subsection{Scenarios}

Distinct scenarios are analyzed in this paper, according to distinct choices of the client relative to the inclination, as already mentioned. These are described in Table 3.

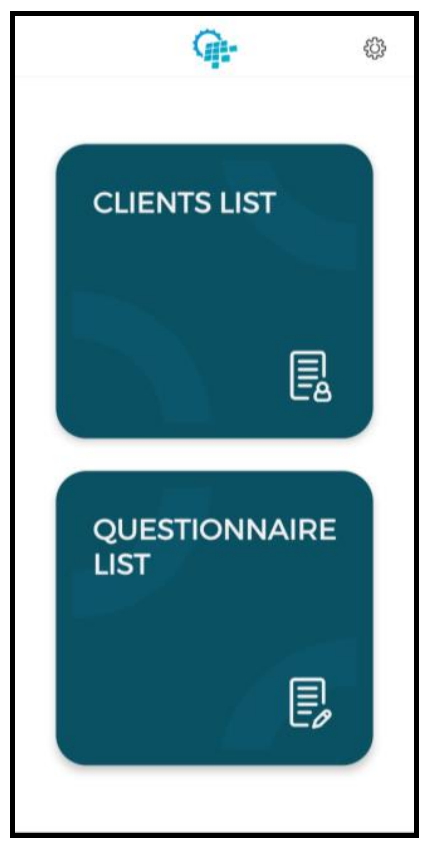

a)

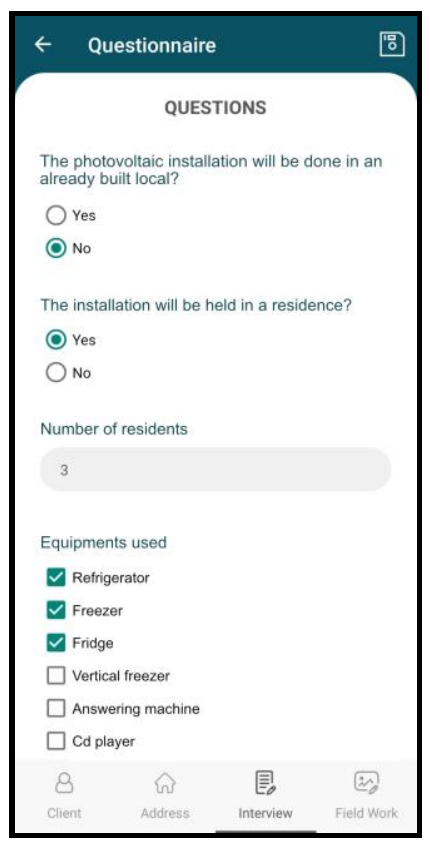

b)

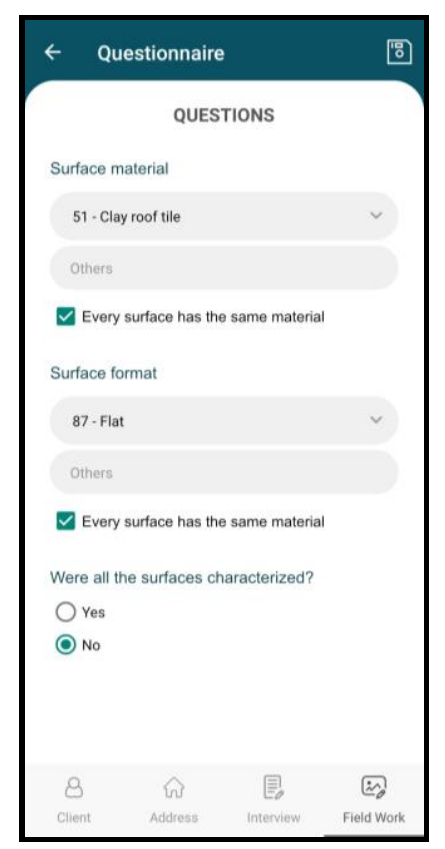

c)

Fig. 6 Screenshots of the app that implements the CAPI, namely a) the main menu, and the screens corresponding to $b$ ) interview with the client and c) fieldwork starting.

Table 3. Tested Scenarios

\begin{tabular}{|c|c|c|}
\hline Scenario & Azimuth & Inclination \\
\hline $\mathrm{SC} 1$ & $28^{\circ}$ & Optimize \\
\hline $\mathrm{SC} 2$ & $28^{\circ}$ & $10^{\circ}$ \\
\hline
\end{tabular}

\section{Analysis and Discussion}

During the analysis of both scenarios, there will be losses during production in which can be described as:

- Resulting from the modules' temperature increase, leading to power losses that can be calculated through the temperature coefficient of power identified in Table 2. 
- Due to modules' mismatch and dust/dirt, where losses arise from differences between the modules which can limit the production, and dirt which limits the available active surface of the modules.

- Ohmic losses in the AC and DC cables, corresponding to losses from the heat generated in the cables by the Joule effect.

- Inverter's nonlinear efficiency, depending on the input power, coming from the photovoltaic plant.

Some other observations are important to do for this project. The energy tariff will rise $2 \%$ each year to simulate its average increase. The module decreases his productions each year which will result in a significant loss in energy production as the years go by and having an investment horizon of 15 years.

\subsection{Scenario 1 (SC1)}

This scenario will analyse the optimum inclination angle $\left(35^{\circ}\right)$, which corresponds to the inclination that allows for the highest global average irradiance throughout the year (according to the PVGIS platform ${ }^{\dagger}$ ). The best economic indicators in this scenario result from installing 111 modules, which is the result of the maximum capacity of the roof with that angle (avoiding self-shading). The results of average production in comparison with the average consumption according to the high (August) and low-season (February) months in the first year can be observed in Fig. 7.

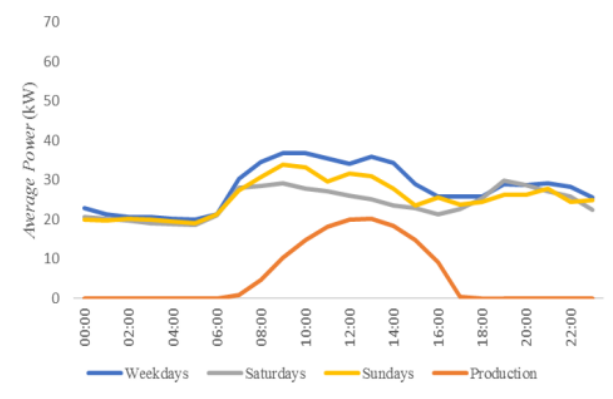

a)

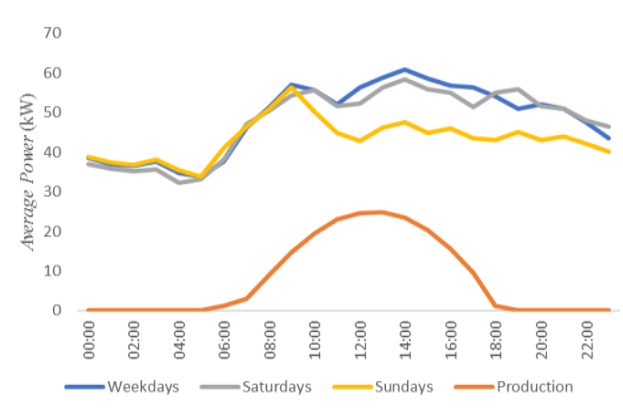

b)

Fig. 7 Graphics demonstrating photovoltaic production average (inclination $35^{\circ}$ ) and consumption in Weekdays, Saturdays, and Sundays in February (a) and August (b).

Table 4 shows the financial and economic indicators of the project with an inclination angle of $35^{\circ}$ that are relevant for the client, as $r$, the interest rate used in the project, NPV, the net present value, and IIR, the internal rate of return, besides the initial investment and the operation and maintenance costs (O\&M).

Table 4. Financial and economic indicators of the project with a $35^{\circ}$ inclination

\begin{tabular}{|c|c|}
\hline Parameter & Value \\
\hline Initial Investment & $47.983,00 €$ \\
\hline O\&M & $500.00 € /$ year \\
\hline$r$ & $6 \%$ \\
\hline
\end{tabular}

${ }^{\dagger}$ https://ec.europa.eu/jrc/en/pvgis 


\begin{tabular}{|c|c|}
\hline NPV & $7.280,81 €$ \\
\hline IRR & $8.2 \%$ \\
\hline
\end{tabular}

\subsection{Scenario 2 (SC2)}

This scenario will analyse the inclination angle chosen by the client $\left(10^{\circ}\right)$. The best economic results in this scenario derive from installing 161 modules, which is the result of the maximum capacity of the roof, again avoiding self-shading. By reducing the inclination angle, a higher number of modules in the roof is possible. The results of average production in comparison with the average consumption according to the high (August) and lowseason (February) months in the first year can be observed in Fig. 8.

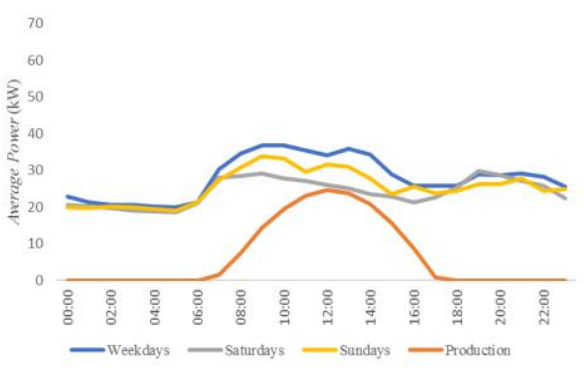

a)

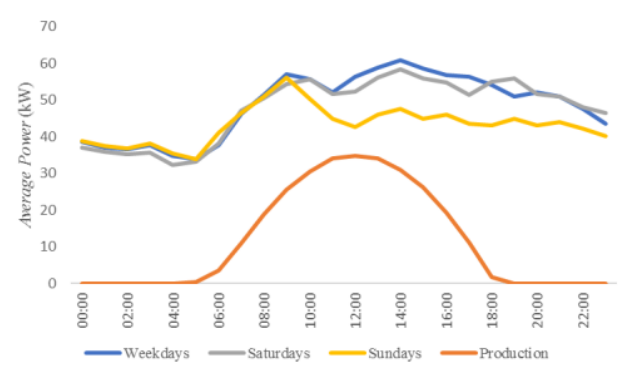

b)

Fig. 8 Graphics demonstrating photovoltaic production average (inclination $10^{\circ}$ ) and consumption in Weekdays, Saturdays, and Sundays in February (a) and August (b).

Table 5 shows the financial and economic indicators of the project that are relevant for the client.

Table 5. Financial and economic indicators of the project with a $10^{\circ}$ inclination

\begin{tabular}{|c|c|}
\hline Parameter & Value \\
\hline Initial Investment & $68.133,00 €$ \\
\hline O\&M & $600.00 € /$ year \\
\hline$r$ & $6 \%$ \\
\hline NPV & $9,088.66 €$ \\
\hline IRR & $7.9 \%$ \\
\hline
\end{tabular}

\subsection{Scenario Comparison}

With both scenarios results presented, it is important to compare them to assess the impact that the app has on the final project. Even though SC2 shows higher NPV values $(9,088.66$ $€$, against $7.280,81 €$ in SC1), SC1 allows a higher IRR (8.2\%, against 7.9\% in SC2) which represents a better investment because the client would have higher profitability. Nevertheless, within the considered horizon investment, and if the client has the required investment capability, higher gains would be achieved with SC2. The evolution of cumulative cash-flows of both scenarios is plotted in Fig. 9. 


\section{Cumulative Cash-Flow}

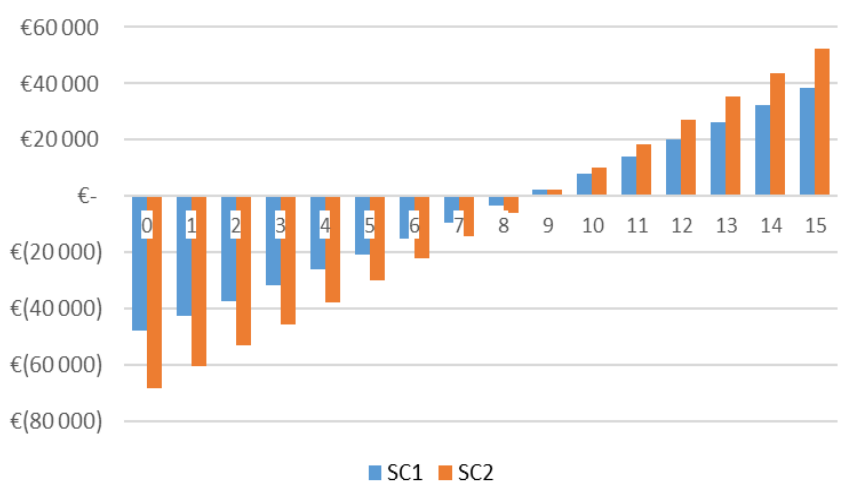

Fig. 9 Comparison of cumulative cash-flows within the investment horizon for both scenarios.

\section{Conclusions}

The definition and implementation of a CAPI methodology provide a valuable tool in PV design, allowing acquiring the relevant data and information from the client that dictates the optimum configuration. This is achieved by guiding the designer/user of the app through the interview and fieldwork. This paradigm will be upgraded for a diversity of legislative and type of use scenarios, namely energy communities and off-grid projects.

\section{Acknowledgement}

This work was financed by European Union, within the program Portugal 2020, in the framework of project LISBOA-01-0247-FEDER-039846.

\section{References}

1. E.D. de Leeuw, J.J. Hox, G. Snijkers, Int. J. Mark. Res., 37, 1-19 (1995)

2. Deutsche Gesellschaft fũr Sonnenergie (DGS), Planning and Installing Photovoltaic Systems: a Guide for Installer, Architects, and Engineers (Earthscan, 2007)

3. International Renewable Energy Agency (IRENA), Future of Solar Photovoltaics: Deployment, Investment, Technology, Grid Integration and Social-Economic Aspects (2019)

4. W.E. Saris, I. N. Gallhofer, Design, Evaluation, and Analysis of Questionnaires for Surveys Research (John Wiley \& Sons, Inc., 2014)

5. M. Weeks, J. Off. Stat., 8, 445 (1992)

6. J. Schräpler, J. Schupp, G. Wagner, DIW Disc. P., 593 (2006)

7. M.S. Bhatia, A. Jaiswal, 2016 6th Int. Conf. - Cl. Syst. B. D. Eng., 326-330 (2016) 
8. R. Poynter, N. Williams, S. York, The Handbook of Mobile Market Research: Tools and Techniques for Market Researchers (Wiley, 2014)

9. S. Sreejesh, S. Mohapatra, M.R. Anusree, Bus. Res. Methods, 143-159 (2014)

10. N.M Bradburn, S. Sudman, B. Wansik, Comput. Environ. Urban Syst., 14, 72 (1990)

11. A.N. Oppenheim, Questionnaire Design, Interviewing and Attitude Measurement (Continuum, 1992)

12. J.M. Converse, S. Presser, Survey Questions: Handcrafting the Standardized Questionnaire, 63 (SAGE Publications, Inc., 1986)

13. J. Rattray, M.C. Jones, J. Clin. Nurs., 16, 234-243 (2007)

14. J. Rowley, Manag. Res. Rev., 37, 308-330 (2014)

15. P.M. Boynton, T. Greenhalgh, BMJ, 328, 1312-1315 (2004)

16. R. Brahme, S. Godbole, R. Gangakhedkar, K.S. Sachdeva, V. Verna, A. Risbud, Indian J. Community Med., 43, 107-112 (2018)

17. Y.W. Kang, Y.S. Ko, Y.J. Kim, K.M. Sung, H.J. Kim, H.Y. Choi, C. Sung, E. Jeong, Public Heal. Res. Perspect., 6, 211-217 (2015)

18. F. Grasso, K. Atkinson, P. Jimmieson, Hum. Assoc. Conf. Affec. Comp. Intel. Inter., 318-323 (2013)

19. C.A. Schoenorn, P.F. Adams, J.A. Peregoy, Vital Health Stat. 10, 257, 1-184 (2013)

20. D. Levinson, A. Paltiel, M. Nir, T. Makovki, Isr. J. Psychiatry Relat. Sci., 44, 85-93 (2007)

21. M. Kohno, Y. Nishizawa, Electoral Survey Methodology: Insight from Japan on Using Computer Assisted Personal Interviews (Routledge, 2016)

22. S. Kulkarni, V. Rajamanickam, Proc. 8th Indian Conf. Hum. Comp. Interaction IHCI, 44-51 (2016)

23. M.C. Macdonald, M. Elliot, T. Chan, A. Kearton, K.F. Shields, J. Bartram, W.L. Hadwen, Water, 8, 574 (2016)

24. J.J. Roberts, A.A.M. Zevallos, A.M. Cassula, Renew. Sustain. Energy Rev., 72, 11041123 (2017)

25. G.M. Masters, Renewable and Efficient Electric Power Systems (John Wiley \& Sons, Inc., 2004) 